\title{
Discussion of Effect of Training Programs on Improving Employees' Communicative Skills ---from the Perspective of Intercultural Communication
}

\author{
Cao Zhiyong ${ }^{1, \text { a }}$ \\ ${ }^{1}$ School of Foreign Languages and Literature, Wuhan University, Wuhan, Hubei, P.R. China \\ aE-mail:Iunwen200433@163.com
}

\begin{abstract}
With the development of economic globalization, the competition among different enterprises all around the world is becoming fiercer and fiercer. Many researchers find that the quality of staff in a company is a crucial factor to improve the productivity of an enterprise. Moreover, in order to improve the productivity of an enterprise, it is both necessary and significant to improve employees' communication skills by means of training programs. In this paper, the author attempts to make a brief analysis of effect of training programs on improving communication skills from the perspective of interpersonal skills cross-cultural communication. In this paper, fours parts are included in total. In the first part, the author argues that the objective of this paper is to find out whether or not the training programs has an effect on improving employees' communication skills; In the second part, both qualitative and quantitative methods to conduct the scientific research has been talked about; In the third part, the experiment results has been shown accordingly; For the last part, the author in this paper made a conclusion that the results are both theoretically accepted and practically right.
\end{abstract}

Key Words:economic globalization; productivity; communication skills; training programs; EckoTours

\section{Introduction}

Mastering effective communication is vital for both employees and organizations as effective communication helps to build positive interpersonal relationship, to prevent communication conflicts, and to improve employees' and organizations' performance. In this circumstance, it is vital for contemporary enterprises to provide effective training program to improve employees' communication skills. With the rapid development of economic globalization, the international tourism is developing very fast. Since international tourism enterprises and their employees often need to communicate with tourists who come from different countries with different cultural backgrounds, therefore, it is vital for employees to process effective intercultural communication skills in order to conduct effective communication with international tourists. EckoTours Australia, an international tourism organization, is providing all kinds of different tourism activities such as ecotourism to international tourists. In current situation, the vast majority of tourists are Chinese people. Due to cultural differences, employees of EckoTours Australia must conduct effective communications with target consumers. Based on this background, the author in this paper will discuss two important areas of communication and then develop a training program for the EckoTours Australia, and the author in this paper holds the view that the objective of this paper is testify the evidence that training programs have an great effect on improving employees' communication skills to a great extent.

\section{Research Methodology}

The author in this part has discussed two different research methodologies. The first one is qualitative methodology; and the second one is quantitative methodology. For qualitative methodology, two important areas of communication have been mentioned. The first one is interpersonal skills; the 
second one is intercultural communication. On the other hand, for quantitative study, two groups such as experimental group and control group are talked about.

\subsection{Qualitative Study}

In this paper, the author argues that interpersonal skills and intercultural communication are two important aspects of communication. For this reason, the two areas of communication should be included into the training programs for employees. Because the training program is very important for improving employees' communication skills to a great extent.Therefore, it is believed that EckoTours can effectively improve its employees' communication competence, and can then make its employees to conduct effective communication with customers so as to improve the productivity of the enterprises accordingly.

\subsubsection{Interpersonal skills}

Among all communication areas, interpersonal skills and intercultural communication are two important areas of communication that should be integrated into the training program for employees. Interpersonal skills describe some skills developed and employed by an individual to conduct effective interpersonal interaction with others suitably (Benson, 2014). In a sense, interpersonal skills generally include all kinds of skills such as listening skills and non-verbal communication and so on. In business field, the interpersonal skills often refer to the abilities mastered by employees to conduct effective communication with its target consumers in order to increase working performance (Quinn, 2013). In the workplace, employees often need to engage and communicate with others. Under this condition, how to establish effective interpersonal interaction relationship has become one of the most important problems that should be considered well. To achieve effective international interaction, it is suggested that the development of good interpersonal skills is very important as effective interpersonal skills bring some positive benefits to employees and organization. Effective interpersonal skills enable people to get along with others, and thus creating positive interpersonal relationship with others. Active listening is one of important interpersonal skills used in communication process. According to Münte and Klump, active listening means that listeners carefully listen to what speakers are saying and observe their behavior and body language, and then make some responses to speakers. By using active listening, listeners often can create effective communication with speakers, and achieve effective interpersonal relationship because speakers often will perceive that they are respected by listeners (Ames et al, 2012). Normally, employees of EckoTours Australia often need to interact with international tourists. Under this condition, it is vital for the employees to obtain an in-depth understanding of tourists' appeals. During this process, the employees needs to master active listening skills. Only by taking active listening, the employees are able to create positive interactive relationship with customers. For example, when customers communicate their complaints about the tourism services to employees, the employees needs to actively listen to customers. In this case, customers will feel that the employees are really listening to them and carefully deal with their complaints rather than perfunctory attitude. By doing so, employees are able to create positive interpersonal relationship with customers. For this, the development of good interpersonal skills is very important.

\subsubsection{Intercultural communication}

Additionally, intercultural communication is also an important area that should be included into the employee training program. Intercultural communication is a communication style in which an individual communicates with others who are from different cultural backgrounds (Chaney and Martin, 2013). This means that intercultural communication is a form of communication engaged by people with different cultural backgrounds. However, some conflicts often will take place during the intercultural communication process because of cultural differences of communications. According to Hofstede' s cultural dimensions theory, national cultures are different, which are embodied in five cultural dimensions, including Power distance index, Uncertainty avoidance index, Individualism vs. collectivism, Masculinity vs. femininity and Long-Term Orientation (LTO) versus short-term orientation (Hofstede,2014). To some extent, the differences in these cultural dimensions often will lead to some unnecessary conflicts and misunderstanding during the communication process (Soares et all, 2011). In this case, employees needs to obtain a more comprehensive understanding of cultural 
differences before conducting communication customers who are from different cultural contexts. EckoTours, as an international tourism organization, often will communicate with different consumers who from different cultural contexts. For this, it is necessary for its employees to understand the differences in national cultures and communication styles before they conduct cross-cultural communication with others. Hall' s High/Low Context theory suggests that national cultures can be subdivided into two contexts, which respectively are high context culture and low context cultures (Hall, 2013). According to Hall' s High/Low Context theory, different context cultures will determine different communication styles. In the low context culture, people often will communicate with others through straightforward approaches, while people who are from high context culture prefer to communicate with others via implicit ways (Richardson \& Smith, 2013). Based on Hall' s High/Low Context theory, people should take different communication ways with others when they conduct intercultural communication with others. For example, Chinese culture belongs to high context culture. During communication process, people like to communicate with others by using implicit ways. For this, the employees of EckoTours need to take implicit way to communicate with Chinese tourists. By doing so, the employees can conduct effective intercultural communication with Chinese tourists. As for countries with low context culture such as America and Canada, people advocate that everything should be communicated clearly and directly. Under this condition, the employees of EckoTours need to communicate relevantly messages to American and Canadian tourists clearly and directly. Based on Hall' s High or Low Context theory, it can be found that the employees of EckoTours needs to master effective intercultural communication skills to conduct effective intercultural communication with tourists who are from difference cultural contexts. Thus, intercultural communication skills should also be integrated into the employee training program.

\subsection{Quantitative Research}

The author in this paper also illustrates the quantitative research methodology on the effect of Australia EckoTours on improving the communicative competence for employees. In this process, two experimental groups coming from two different companies are involved. The first group is called experimental group; and the second one is controlled group. Moreover, both participants in two groups are 100, they are similar in age, ranging from 20 to age 25. And the author in this experiment makes use of the independent $\mathrm{T}$ test to acquire the data. Employees coming from experimental groups are arranged to communicate with customers; and those from controlled do not. And there is a big difference between these two groups one year later. In experimental group, $\mathrm{P}=0.014<0.05$, which shows that there is a positive correlation between the performance before the experiment and the performance after experiment; on the other hand, in controlled group, $\mathrm{P}=0.214>0.05$, which shows that there is a negative correlation between the performance before the experiment and the performance after experiment.

\section{Experimental Results}

As the author has mentioned above, both qualitative and quantitative researches has shown that Australia EckoTours has a positive effect on improving the communicative competence for employees. Since the employees of EckoTours often will carry out communication with tourists from different countries, especially China, therefore, it is very important for Australia EckoTours to develop effective communication training program to further improve its employees' interpersonal communication skills. When developing the training program for employees, the development of good interpersonal skills and the cultivation of intercultural communication skills should be regarded as two important contexts integrated into the employee training program.

In order to carry out the training program for employees effectively, the following actions should be taken into account. First of all, EckoTours should arrange professional training personnel to train employees' interpersonal interaction skills. For example, during the process of employee training, it is necessary to make employees to know the importance and implication of the use of active listening skills and non-verbal communication skills in the communication process. Additionally, EckoTours 
needs to provide some skills for employees to conduct effective active listening when communicating with customers. By doing so, the organization can achieve the purpose of improving employees' interpersonal communication skills. Secondly, the training course also should include some intercultural communication trainings. For example, the company should provide some courses that introduce the differences between different cultures, and the courses that illustrate how people who are from different cultural backgrounds communicate with others. By providing these training courses, the employees are able to understand the impacts of cultural differences on communication ways, and thus take effective communication ways to conduct interpersonal communication with the customers from different cultural contexts. Thirdly, the company also needs to provide some practicing courses for employees in order to develop their interpersonal skills and intercultural communication ability. For example, in order to develop employees' intercultural communication ability, the company also can provide simulative scenes for employees to practice their intercultural communication skills. By using simulative scenes training, employees can further know how to conduct effective intercultural communication with customers who are from different national cultures. Finally, the company should also arrange relevant tests to examine the outcomes of the implementation of the employee training program. Through tests, the company can well understand the actual results after the implementation of the training program, and thus further adjust the training program to further improve employees' communication ability.

\section{Conclusion}

To sum up, the author in this paper has proved that international EckoTours has a positive effect on the improvement of employees' communicative competence both qualitatively and quantitatively. Thus, this international program should be adopted accordingly.

This paper has discussed some important aspects of communication. The author also argues that interpersonal skills and intercultural communication are two important aspects of communication. For this, these two areas of communication should be included into the training program for employees. In order to effectively improve employees' interpersonal skills and intercultural communication ability in the communication process, the specific actions to implement the training program have been provided in this paper. By providing the training program, it is believed that EckoTours can effectively improve its employees' communication ability, and thus make its employees to conduct effective communication with customers.

\section{References}

[1] Ames, D \& Maissen, L \& Brockner, . The role of listening in interpersonal influence. Journal of Research in Personality,2012.

[2] Benson, B. Domain of Competence: Interpersonal and Communication Skills. Academic Pediatrics [M]. 2014.

[3] Chaney, L \& Martin, Intercultural Business Communication (6th Edition). 2013.

[4] Guo Qingguang. Course of Communication [M]. Beijing: Remin University of China Press, 2014.

[5] Hofstede.Culture's Consequences: comparing values, behaviors, institutions, and organizations across nations (2nd ed.). Thousand Oaks, CA: SAGE Publications, 2014.

[6] Jiang Qiyan, Public Opinions of Social Networks, Sun Yat-sen University Press,2014.

[7] Li Liangrong. Introduction of Journalism [M]. Shanghai: Fudan University Press, 2015.

[8] Quinn, K. The Importance of Resource and Interpersonal Skills in the Hospitality Industry.Journal of Foodservice Business Research 16 (5), Pages 439-447,2013. 
[9] Richardson, P. M \& Smith,W.S. The influence of high/low-context culture and power distance on choice of communication media: Students' media choice to communicate with Professors in Japan and America[M]. International Journal of Intercultural Relations, 31(4): 479-501, 2013.

[10] Soares, A \& Farhangmehr, M \& Shoham, A.Hofstede's dimensions of culture in international marketing studies. Journal of Business Research, 60 (3), Pages 277-284,2011.

[11] Shi Rongrong. Real communication in Virtual World---A brief Analysis of Interpersonal Communication[M], 2014.

[12] Sun Yingchun. Inter-cultural Communication: Global and Indigenous Perspectives. Beijing: Peking University Press, 2015.

[13] Thomas L. McPhail, Global Communication: Theories, Stakeholders and Trends. Communication University of China Press,2016. 